\title{
Compliance with sharps waste standards by a sample of Sydney acupuncture premises
}

\author{
Louise Blundell ${ }^{\mathrm{A}}$, Toni Cains ${ }^{\mathrm{B}}$, \\ Kelly-Anne Ressler ${ }^{\mathrm{B}, \mathrm{D}}$ and \\ Mark J. Ferson ${ }^{\mathrm{B}, \mathrm{C}}$

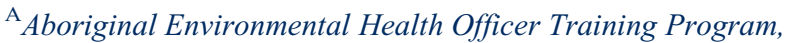 \\ NSW Department of Health \\ ${ }^{\mathrm{B}}$ Public Health Unit, South Eastern Sydney Illawarra Area \\ Health Service \\ ${ }^{\mathrm{C}}$ School of Public Health and Community Medicine, \\ The University of New South Wales \\ ${ }^{\mathrm{D} C o r r e s p o n d i n g ~ a u t h o r . E m a i l: ~ K e l l y-A n n e . R e s s l e r @ s e s i a h s . ~}$ \\ health.nsw.gov.au
}

\begin{abstract}
Aim: To examine current practices with regard to the safe collection, storage and disposal of sharps waste in acupuncture premises and to determine compliance with the NSW Public Health (Skin Penetration) Regulation 2000 and the NSW Health Skin Penetration Code of Best Practice. Methods: A random sample of acupuncturists in the City of Sydney local government area was selected and surveyed using a structured questionnaire. Results: All 26 acupuncturists surveyed had sharps disposal bins and complied with the Regulation, but the following elements of the Code were not uniformly followed: regular disposal of sharps $(77 \%)$, disposal through a waste contractor $(23 \%)$ and placement of bins out of reach of visitors $(8 \%)$. Conclusion: Regular disposal of sharps containers in acupuncture premises could be improved.
\end{abstract}

Contaminated waste, such as needles used to penetrate the skin, is produced by acupuncture procedures. These needles are potentially hazardous to human health if a needlestick injury occurs, for example as a result of the handling of a sharps disposal bin that is overflowing. This may result in infection with a bloodborne virus such as HIV, hepatitis $\mathrm{B}$ or hepatitis $\mathrm{C} .^{3}$ Contaminated sharps are considered a bio-hazard and are a risk to the community, especially to children, if they are accessible. ${ }^{2}$

The transmission of bloodborne viruses following needlestick injuries, ${ }^{4-6}$ and more rarely acupuncture, has been documented. ${ }^{7,8}$ The risk of contracting a bloodborne virus infection after a needlestick injury depends on the probability of the needle having been used on an infected person and the amount of viable virus transferred within the injury. ${ }^{9}$ When the source is positive, the transmission rate for hepatitis B is estimated to be 1 in 3 , while for hepatitis C it is 1 in 30 and for HIV it is 1 in $300 .^{10}$

In recent years, environmental health officers from NSW public health units (PHUs) had observed that sharps disposal bins in acupuncture premises were often overfilled with sharps and located in areas where children could access them. In addition, the operators had no waste contract for disposing of sharps bins. These anecdotal observations demonstrated a need to undertake a survey to assess the collection, storage and disposal of sharps waste in acupuncture premises. We are not aware of any other survey of sharps disposal in acupuncture premises since the introduction of the Skin Penetration Regulation in 2000. The two aims of the survey were: to examine current practices in regard to the safe collection, storage and disposal of sharps waste in acupuncture premises; and to determine the level of compliance with the Skin Penetration Regulation and the Code of Best Practice.

\section{Methods}

The survey was conducted in the City of Sydney local government area (LGA). For the purpose of this study, acupuncture is defined as an ancient Chinese form of treatment which involves inserting fine needles into selected points of the body. ${ }^{11}$

A pilot study of seven acupuncture premises in the St George area, chosen from the Yellow Pages telephone directory, was used to test the survey instrument. A random sample of approximately $50 \%$ of acupuncturists was 
selected from the City of Sydney Council's Skin Penetration Register. Where premises from the list were visited and were closed or no longer operating other premises in close proximity were selected. The aims and objectives of the survey were explained to the managers prior to the survey being undertaken; however, managers were not forewarned of the survey. The manager of each acupuncture premise was interviewed face-to-face using a structured questionnaire. The questionnaire asked for details on: the type of procedures carried out; the number of sharps generated; the method of disposal of sharps; possession of the Skin Penetration Regulation and the Code of Best Practice; details of qualifications held by the acupuncturist; and proficiency in the English language. No ethics approval was sought for this compliance survey.

All data was coded and entered into a statistical database computer software package (SPSS, version 17.0, Chicago, IL, USA) by one individual to maintain uniformity and participant confidentiality.

\section{Results}

The survey was undertaken between June and September 2009. Twenty-six acupuncturists (52\%) were selected from the 50 identified in the Skin Penetration Register. Of these, four were not available; two were no longer in operation and two were closed on the day of inspection. These four premises were substituted with acupuncture premises that were in close proximity to them, two of which were not registered with the City of Sydney Council.

All premises were privately owned and operated. The premises commonly had multiple rooms or areas for acupuncture treatments. Most offered additional services including traditional Chinese medicine, massage and Chinese herbal medicine.

Eight acupuncture premises (31\%) had been in operation for less than 5 years, five (19\%) for 5-9 years, eight (31\%) for 10-19 years and five (19\%) had been operating for longer than 19 years.

All managers interviewed were also practicing acupuncturists. Twenty-four (92\%) stated that English was not their first language, although $21(81 \%)$ stated that they could read and write in English. The managers for whom English was not their first language were still able to be interviewed in English.

All 26 premises used disposable needles and had sharps disposal bins. The median number of sharps generated per day was 40 (range 1-200), although many managers had difficulty giving a precise answer to this question. The median number of sharps disposal bins was two (range 1-12). Sharps disposal bins ranged in capacity from 1 to 20 litres.
Table 1. Location of sharps waste disposal bins described in a compliance survey of 26 acupuncture premises in the Sydney local government area, 2009

\begin{tabular}{lcc}
\hline Location & Number & $\%$ \\
\hline On floor & 12 & 46.2 \\
On desk & 3 & 11.5 \\
On shelf & 3 & 11.5 \\
On cupboard & 1 & 3.8 \\
On bench & 1 & 3.8 \\
On containers & 1 & 3.8 \\
On trolley & 1 & 3.8 \\
Under bed & 1 & 3.8 \\
Under sink & 1 & 3.8 \\
Unknown & 2 & 7.7 \\
Total & 26 & 100 \\
\hline
\end{tabular}

Twenty-one premises ( $81 \%$ ) had a sharps disposal bin in each treatment room. The remaining premises had the bins nearby to the treatment rooms. Half kept them on the floor, of which one was stored under the treatment bed. The majority of others stored the used containers on a desk or shelf (Table 1).

Eight acupuncturists (31\%) had never disposed of their sharps bins. These eight premises generated a median of 15 sharps per day (range 1-150). For those who did dispose of their sharps bins, most $(n=14,54 \%)$ did this at least once per year, and three (12\%) disposed of sharps bins approximately every 2 years. One acupuncturist only disposed of sharps every 2-3 years.

Only six premises $(23 \%)$ had a licensed waste contract for the removal of waste and the same number could produce records of the removal. One had a handwritten note from a local physiotherapist about the sharps waste removal from his premises that had last been undertaken some 3 years previously.

Although seven acupuncturists stated they had copies of the Skin Penetration Regulation and the Code of Best Practice, only five (19\%) could produce the documents (Table 2).

A number of questions were asked about the acupuncturists' qualifications. Only one had no formal qualifications and stated that they had been trained in the profession by relatives. Details were obtained about whether the qualifications were obtained overseas or in Australia. The most common qualification, a Bachelors Degree obtained in China, was held by 13 acupuncturists (50\%). Five acupuncturists (19\%) had obtained a Masters Degree in Australia (Table 3).

Twenty-four premises (92\%) were registered with the City of Sydney Council and $21(73 \%)$ said that they had been 
Table 2. Selected responses to survey questions by the managers of 26 acupuncture premises in the Sydney local government area, 2009

\begin{tabular}{|c|c|c|c|c|c|c|c|}
\hline Response & $\begin{array}{l}\text { English first } \\
\text { language } \\
n \quad(\%)\end{array}$ & $\begin{array}{l}\text { Can read and } \\
\text { write English } \\
n \quad(\%)\end{array}$ & $\begin{array}{l}\text { Registered with City } \\
\text { of Sydney Council } \\
n \quad(\%)\end{array}$ & $\begin{array}{l}\text { Code } \\
\text { Sighted } \\
n \quad(\%)\end{array}$ & $\begin{array}{l}\text { Regulation } \\
\text { sighted } \\
n \quad(\%)\end{array}$ & $\begin{array}{l}\text { Waste } \\
\text { contract } \\
n \quad(\%)\end{array}$ & $\begin{array}{c}\text { Disposal records } \\
\text { sighted } \\
n \quad(\%)\end{array}$ \\
\hline Yes & (8\%) & $21 \quad(81 \%)$ & $24 \quad(92 \%)$ & $5 \quad(19 \%)$ & $5 \quad(19 \%)$ & $6 \quad(23 \%)$ & $6 \quad(23 \%)$ \\
\hline No & $24 \quad(92 \%)$ & $5 \quad(19 \%)$ & $2 \quad(8 \%)$ & $21 \quad(81 \%)$ & $21 \quad(81 \%)$ & $20 \quad(77 \%)$ & $20 \quad(77 \%)$ \\
\hline Total & 26 (100\%) & 26 (100\%) & 26 (100\%) & $26(100 \%)$ & $26(100 \%)$ & 26 (100\%) & 26 (100\%) \\
\hline
\end{tabular}

Table 3. Highest qualifications of acupuncturists surveyed in 26 acupuncture premises in the Sydney local government area, 2009

\begin{tabular}{|c|c|c|c|}
\hline \multirow[t]{2}{*}{ Qualifications } & \multicolumn{2}{|c|}{$\begin{array}{c}\text { Country where } \\
\text { qualification obtained }\end{array}$} & \multirow[t]{2}{*}{$\begin{array}{c}\text { Tota } \\
N\end{array}$} \\
\hline & $\begin{array}{c}\text { Australia } \\
n\end{array}$ & $\begin{array}{c}\text { China } \\
n\end{array}$ & \\
\hline No formal qualifications & - & - & 1 \\
\hline Diploma & 2 & 1 & 3 \\
\hline Bachelors Degree & 3 & 13 & $15^{\mathrm{a}}$ \\
\hline Masters Degree & 5 & 2 & 7 \\
\hline Total & 10 & 16 & 26 \\
\hline
\end{tabular}

${ }^{a}$ One person had two Bachelors Degrees, one obtained in China and one in Australia.

inspected by the Council within the previous year (Table 3). The two premises that were not registered had opened their operations without any development application to Council and appeared to be unaware that they needed to be registered. Both had been in operation for 2 years or less. Neither of these premises had a waste contract for the disposal of sharps, nor did the managers have knowledge of the Skin Penetration Regulation or Code of Best Practice.

\section{Discussion}

Used needles are potentially hazardous to human health if exposure occurs. The reporting of needlestick injuries and bloodborne virus transmission in acupuncture settings is rare and a systematic review by Ernst and Sherman concluded that there is a modest association between acupuncture and hepatitis C. ${ }^{11}$ Looking at the statistics of needlestick injuries in an Australian hospital setting, Bi et al in 2008 reported that $11 \%$ were a result of the incorrect handling of sharps. ${ }^{12}$

In August 2000, NSW Health introduced the Skin Penetration Regulation whereby for the first time it was a requirement to have a sharps bin in a skin penetration premises. A previous survey into the infection control and hygiene practices within skin penetration premises undertaken by Bouwman et al in 1991 found that only $32 \%$ of acupuncture premises had a sharps bin; a follow-up survey in 1994 found only $53 \%$ of premises had a sharps waste bin. ${ }^{13}$ Our finding that all acupuncturists had a sharps waste bin suggests that there has been a large improvement, we presume as a direct result of the legal requirement adopted in 2000 , and the ensuing regulation and education undertaken by local councils and PHUs.

Nearly all acupuncturists stored their sharps in yellow Australian Standards approved sharps containers that are puncture proof, waterproof and leakproof. One acupuncturist, however, was storing used sharps in a drink bottle and one acupuncturist from the pilot sample had stored used sharps in a used 'bacterial baby wipes' container. Although this information was not formally recorded for this study, the overfilling of the sharps containers to the point where the sharps were 'sticking out' of the lid was observed.

The Skin Penetration Code of Best Practice was released in 2001 and it is this document that provides guidance on waste disposal. Elements of this Code, in particular the recommendation to have a sharps waste contract and to ensure sharps waste containers are located in a safe position, could be incorporated into a revision of the Skin Penetration Regulation to promote safe storage and disposal of sharps.

Box 1. Recommendations to skin penetration operators contained in Section 6 of the Skin Penetration Code of Best Practice

- Ensure there is an accessible sharps container for the disposal of sharps as close as practical to the point of generation

- Immediately dispose of sharps as this protects operators, staff and clients from potential injury

- Ensure that sharps containers are not accessible to visitors, particularly children

- Ensure that sharps containers are not overfilled

- Ensure that sharps containers are sealed and stored for disposal

- Ensure that sharps are not forced into sharps containers

- Do not re-sheath used needles prior to disposal

- Do not remove sharps once placed into a sharps container

Source: NSW Health. Skin Penetration Code of Best Practice. March 2001. 
Another finding was that eight (31\%) of the acupuncturists surveyed had never disposed of their sharps waste, and it was common to witness premises with multiple full yellow Australian Standards approved sharp disposal bins that had never been disposed of. Further, the Code of Best Practice recommends that sharps containers are not accessible to visitors, especially to children, and this survey found containers located on the floor. These acupuncture premises would not meet this recommendation unless other steps were in place to prevent child access.

The recommended method for the removal of contaminated waste is by a licensed waste contractor; however, only six operators had a formal licensed waste contract. Some acupuncturists claimed that they had an informal arrangement with either a general practice or a local public hospital where they were able to dispose of their sharps waste at minimal cost, however, none of these had any record of the disposal.

In 1994, Bouwman et al found that $40 \%$ of acupuncture premises had a contract for the removal of sharps waste. This is higher than what was found in this study some 15 years later, however, the survey population may have differed and this was a much smaller study.

Only $19 \%$ of the acupuncturists surveyed had a copy of the Skin Penetration Regulation and the Code of Best Practice. This finding indicates a need for industry-wide education. Also, unregistered acupuncturists in this sample were lacking in knowledge of appropriate professional regulations and guidelines. They had also reported that they were unaware of the requirement to be registered with Council. It is likely that there are other premises operating in NSW and an opportunity for industry-wide education should be mindful to include these unregistered acupuncturists.

Many acupuncturists appeared to be highly qualified; however, because we were not able to access or verify qualifications, we may have overreported the level of qualifications held. It should be noted that the majority of qualifications held were obtained overseas, so education about local regulations needs to occur outside of the education sector.

This is a small survey in a limited geographical area of Sydney and the results may not be indicative of all acupuncturists across NSW. There is a further limitation to the survey as the Skin Penetration Register, from which the sample was drawn, is not a complete list of acupuncturists in the area. This is because some premises are not registered with the Council and are therefore not included on the Register. The sample surveyed may therefore underrepresent the actual number of practising acupuncturists in the City of Sydney LGA and may also draw from a sample of relatively well-informed practices.

\section{Conclusion}

This small compliance survey found it encouraging that acupuncturists in the City of Sydney have sharps waste disposal bins and appear to hold qualifications in acupuncture. However, the regular disposal of sharps waste should be improved and this could be achieved by providing education to acupuncturists regarding the Skin Penetration Regulation and the Code of Best Practice and by translating these documents into other languages. Sections of the Code of Best Practice, particularly those relating to the safe collection storage and disposal of sharps, should be formally incorporated into the Skin Penetration Regulation.

\section{Acknowledgments}

The authors would like to thank Neil Williamson and the City of Sydney Council for the provision of their Skin Penetration Register and for valuable comments on the manuscript. We also gratefully acknowledge the managers of the acupuncture premises surveyed for this research.

\section{References}

1. NSW Health. Public Health (Skin Penetration) Regulation 2000. Available from: http://www.health.nsw.gov.au/pubs/2000/pdf/ skin_pen_reg_2000.pdf (Cited 18 September 2010.)

2. NSW Health. Skin Penetration Code of Best Practice. March 2001. Available from: http://www.cityofsydney.nsw.gov.au/ Business/documents/Health/SkinPenetrationCodeOfPractice. pdf (Cited 19 May 2011.)

3. Hutin Y, Hauri A, Chiarello L, Catlin M, Stilwell B, Ghebrehiwet $\mathrm{T}$ et al. Best infection control practices for intradermal, subcutaneous, and intramuscular needle injections. Bull World Health Organ 2003; 81(7): 491-500.

4. Ridzon R, Gallagher K, Ciesielski C, Ginsberg MB, Robertson BJ, Luo CC et al. Simultaneous transmission of human immunodeficiency virus and hepatitis $\mathrm{C}$ virus from a needle-stick injury. $N$ Engl J Med 1997; 336(13): 919-22. doi:10.1056/NEJM199703273361304

5. Baldo V, Floreani A, Dal Vecchio L, Cristofoletti M, Carletti M, Majori S et al. Occupational risk of blood-borne viruses in healthcare workers: a 5-year surveillance program. Infect Control Hosp Epidemiol 2002; 23(6): 325-7. doi:10.1086/502059

6. Do AN, Ciesielski CA, Metler RP, Hammett TA, Li J, Fleming PL. Occupationally acquired human immunodeficiency virus (HIV) infection: national case surveillance data during 20 years of the HIV epidemic in the United States. Infect Control Hosp Epidemiol 2003; 24(2): 86-96. doi:10.1086/502178

7. Kent GP, Brondum J, Keenlyside RA, LaFazia LM, Scott HD. A large outbreak of acupuncture-associated hepatitis B. Am J Epidemiol 1988; 127(3): 591-8.

8. Wiwanitkit V. HIV infection after Chinese traditional acupuncture treatment. Complement Ther Med 2003; 11(4): 272. doi:10.1016/S0965-2299(03)00141-9

9. Wittmann A, Kralj N, Köver J, Gasthaus K, Hofmann F. Study of blood contact in simulated surgical needlestick injuries with 
single or double latex gloving. Infect Control Hosp Epidemiol 2009; 30(1): 53-6. doi:10.1086/593124

10. UK Departments of Health. Guidance for clinical health care workers: protection against infection with blood-borne viruses. 1998. Available from: http://www.dh.gov.uk/en/Publication sandstatistics/Publications/PublicationsPolicyAndGuidance/ DH_4002766 (Cited 24 September 2010.)

11. Ernst E, Sherman KJ. Is acupuncture a risk factor for hepatitis? Systematic review of epidemiological studies. J Gastroenterol
Hepatol 2003; 18(11): 1231-6. doi:10.1046/j.14401746.2003.03135.x

12. Bi P, Tully PJ, Boss K, Hiller JE. Sharps injury and body fluid exposure among health care workers in an Australian tertiary hospital. Asia Pac J Public Health 2008; 20(2): 139-47.

13. Bouwman R, Cannata S, Bek M, Fett M. Infection control and hygiene practices in skin penetration businesses. NS W Public Health Bull 1998; 9: 47-50. doi:10.1071/NB98014 